\title{
CORRECTION
}

Tsurumi H, et al:

A case of leiomyoblastoma (epithelioid leiomyosarcoma) of the greater omentum

Gastroenterol Jpn 1991;26(3):370-375

\section{Page 373}

Due to a poor process of printing, Figure 5(a) has appeared in bad shape. The Figure 5(a) is printed below as an ideal reproduction of the original photograph.

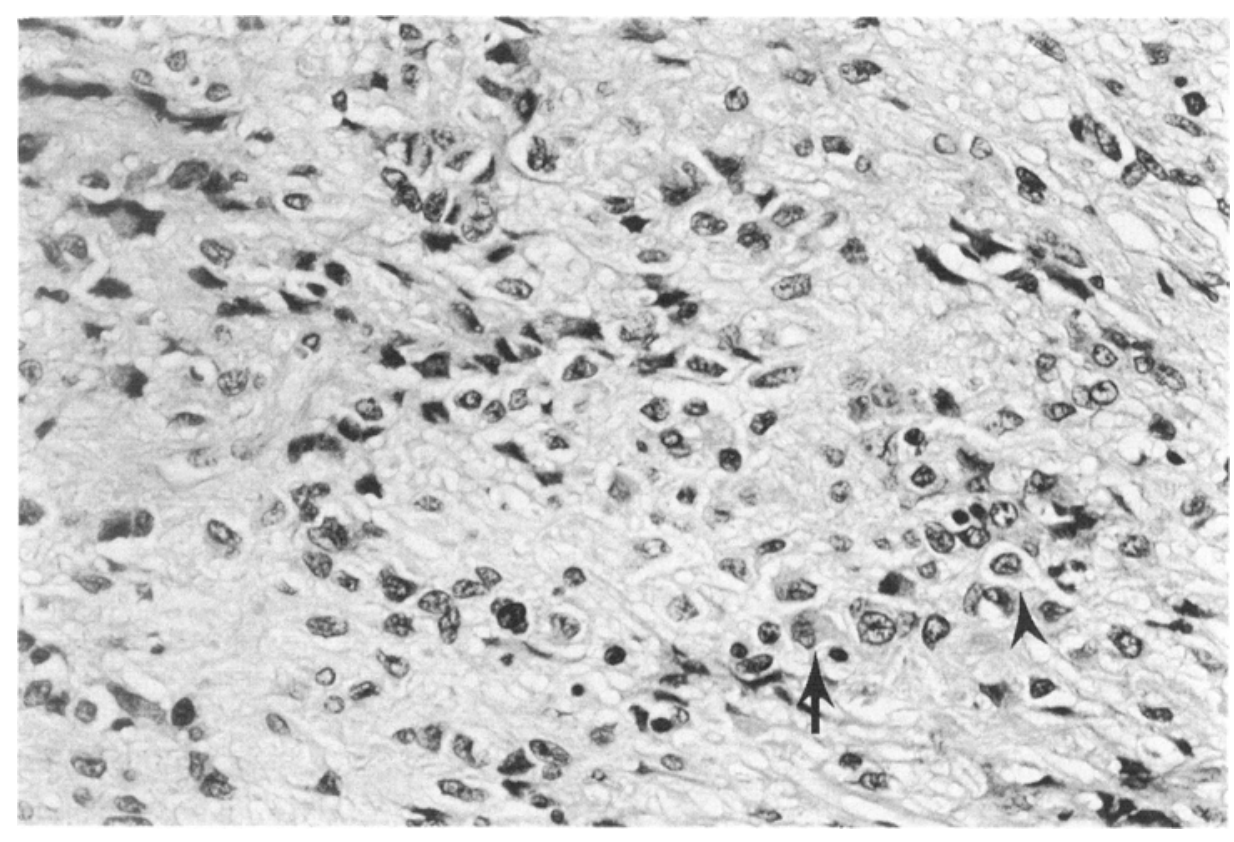

\section{Fig. 5}

Microscopic examinations showed a leiomyoblastoma. Tumor was composed of sheets of round or spindle cells with abundant eosinophilic cytoplasm (arrows) and in some cells, perinuclear clear spaces (arrow heads). (A) H\&E (B) Vimentin, $(\times 40)$ 